Indexed by

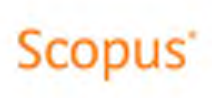

\title{
RESEARCH OF THE POSSIBILITY OF TRANSMISSION OF LIQUEFIED NATURAL GAS THROUGH A PIPELINE BY A NON-PRESSURE METHOD
}

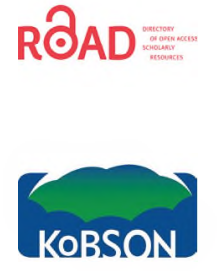

8oogle
Zhmakin Vitaly Anatolievich

Southwest State University,

Faculty of Construction and

Architecture, Department of

Heat, Gas and Water Supply,

Kursk, Russia

\author{
Budnikov Victor Sergeevich \\ Southwest State University, \\ Faculty of Construction and \\ Architecture, Department of \\ Heat, Gas and Water Supply, \\ Kursk, Russia
}

Key words: liquefied natural gas, gas supply, cryogenic liquid, isothermal tank, methane tanker, cryogenic pipeline, two-phase flow, vapor content, saturation temperature, saturated vapor pressure doi:10.5937/jaes0-31856

Cite article:

Anatolievich Vitaly Z., Sergeevich Victor B. (2021) RESEARCH OF THE POSSIBILITY OF TRANSMISSION OF LIQUEFIED NATURAL GAS THROUGH A PIPELINE BY A NONPRESSURE METHOD, Journal of Applied Engineering Science, 19(4), 1114 - 1119, DOI:10.5937/ jaes0-31856

Online aceess of full paper is available at: www.engineeringscience.rs/browse-issues 


\title{
RESEARCH OF THE POSSIBILITY OF TRANSMISSION OF LIQUEFIED NATURAL GAS THROUGH A PIPELINE BY A NON-PRESSURE METHOD
}

\author{
Zhmakin Vitaly Anatolievich*, Budnikov Victor Sergeevich \\ Southwest State University, Faculty of Construction and Architecture, Department of Heat, Gas and Water \\ Supply, Kursk, Russia
}

This article discusses the problems of transmission of liquefied natural gas through a non-pressure pipeline from a stationary storage facility to a transport cryogenic tank and ways to solve them. Theoretical studies have been carried out, including mathematical modeling of thermal and hydrodynamic processes during the transmission of liquefied natural gas through a pipeline by a non-pressure method.

Key words: liquefied natural gas, gas supply, cryogenic liquid, isothermal tank, methane tanker, cryogenic pipeline, two-phase flow, vapor content, saturation temperature, saturated vapor pressure

\section{INTRODUCTION}

Nowadays, liquefied natural gas (LNG) has taken a strong position in the energy market. One of the main reasons for this is the fact that the main consumers of natural gas were cut off from the places of its production, which necessitates the construction of liquefaction plants in places of promising fields and the transportation of LNG by sea in methane tankers [1] to [3]. LNG production is concentrated mainly in northern Africa (Algeria, Libya), Indonesia, Malaysia, the Persian Gulf, and Australia. The main consumers of LNG are Japan, South Korea, France, Spain, Belgium, the USA, which are both an importer and an exporter [1] to [3]. Russia also possesses the largest natural gas fields located in remote areas (the Barents Sea, the shelf of the Kara Sea, Sakhalin Island, etc.), which are unfavorable for the construction of trunk gas pipelines. Therefore, two large natural gas liquefaction plants have already been built there and continue to increase their capacity - on Sakhalin Island and on the Yamal Peninsula [4] to [6]. For intercontinental LNG transport, a fleet of methane tankers with tank volumes of up to 120 thousand $\mathrm{m} 3$ and more has been built, which is equivalent to 72 million $\mathrm{m} 3$ of conventional gas. Methane carriers are being designed to transport over $\mathbf{2 0 0}$ million $\mathrm{m} 3$ of gas in one trip. There are tankers with ball tanks built into the deck; ships in which LNG is stored directly in insulated holds; special reinforced methane carriers for navigation in arctic ice conditions [1], [4]. Unloading and filling of methane tankers is carried out in receiving terminals through process pipelines by various methods using overpressure. The most commonly used of these are the transfer of LNG by means of pumps, pressurization of an inert gas with a lower boiling point, or pressurization of LNG vapors obtained in an evaporator [7] to [8]. However, LNG is a cryogenic liquid that boils at a temperature of $161.5^{\circ} \mathrm{C}$ below zero at atmospheric pressure, which causes heat gains from the environment. Due to heat gains, LNG evaporates, forming a vapor-liquid flow. In addition, LNG can boil if the pressure in the pipeline drops below the saturated vapor pressure of the LNG, which occurs in the suction pipeline and leads to the disruption of the pump [9] to [10]. LNG delivery from a large storage facility by pressurizing an inert gas with a lower boiling point or pressurizing LNG vapors obtained in the evaporator is limited by the permissible rise in pressure in the storage facility, which can lead to rupture of its walls [11] to [12]. Therefore, in some cases, it is more expedient to use the non-pressurized method of LNG transfer due to the difference in levels, for example: when loading a methane tanker from a storage located on a hill. At the same time, there are no energy costs and the need for expensive cryogenic pumps that require maintenance, and there is no need to raise high pressure in the storage. This method is widely used when unloading liquefied petroleum gases from railway tanks into storage (Fig. 1) [13]. The drained tank and the tank to be filled are connected by pipelines of the vapor and liquid phases. In communicating vessels, the liquid is set at the same level, so the liquid phase will flow into the downstream reservoir. At the same time, in order to create a sufficient discharge rate at the same temperatures and pressures in the tank and the reservoir, it is necessary that due to the hydrostatic head (due to the difference in levels) a pressure difference of at least $0.7-1.0 \mathrm{kgf} / \mathrm{cm} 2$ is created; the minimum required value of the hydrostatic head is $13-20$ $\mathrm{m}$ of the liquid column (taking into account that the density of liquefied hydrocarbon gases is about $582 \mathrm{~kg} / \mathrm{m} 3$ ) [13]. When LNG is pumped or pressurized with vapors, the excess pressure created by them increases the LNG saturation temperature, ensuring that the liquid is subcooled to the saturation temperature, thereby preventing LNG boiling up in the pipeline. When transferring LNG due to the difference in levels (see Fig. 1), the available head may be insufficient to ensure that the LNG is subcooled to saturation temperature. Therefore, in a certain section from the entrance to the pipeline, LNG reaches 
a saturation state and boils, creating steam plugs in vertical pipelines or an upward movement of steam, which prevents the transfer of LNG through the pipeline [13].

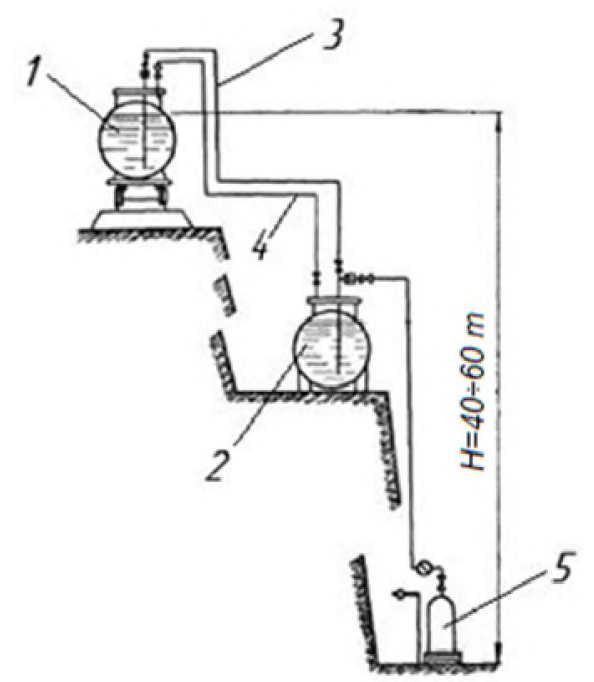

Figure 1: Transfusion of liquefied hydrocarbon gases due to the difference in levels

1 - tank; 2 - stationary tank; 3 - liquid phase pipeline;

\section{4 - gaseous form pipeline, 5 - cylinder}

In this case, various LNG flow regimes can take place, starting from a liquid flow with vapor bubbles and ending with a vapor flow containing liquid droplets. The modes differ in the mechanisms of heat transfer and in the spatial distribution of the vapor and liquid phases. In a vertical pipeline (Fig. 2), bubble, slug, annular or dispersed annular, emulsion flow regimes can exist. Bubble flow occurs at low flow rates, slug - at moderate steam rates and relatively low flow rates; dispersed-annular and emulsion - at high steam contents and high flow rates [14].
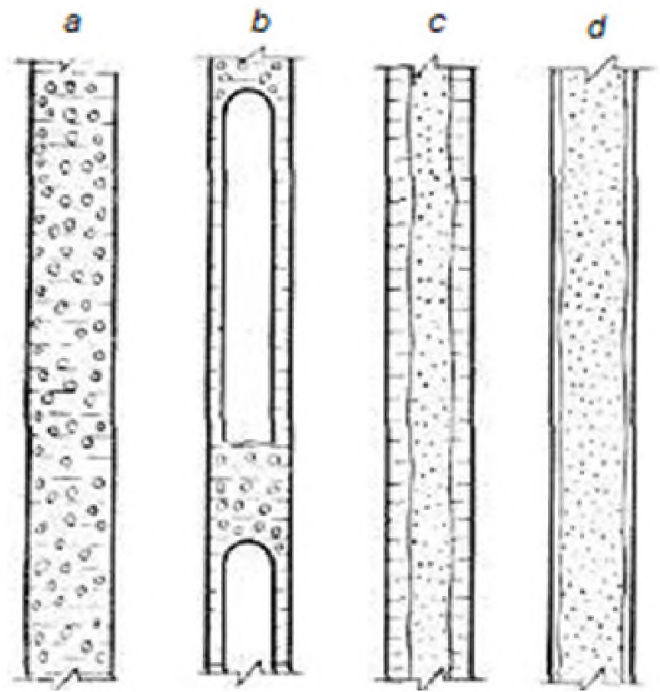

Figure 2: Modes of vapor-liquid flow in vertical pipes a - bubble; $b$ - slug; c - circular; $d$ - emulsion
In the riser, the vapor velocity of the LNG is lower than that of the liquid phase, which causes a higher hydraulic resistance. At low velocities of the liquid phase, a lifting movement of steam is observed in the drop pipe. This phenomenon significantly complicates the transportation of LNG by the gravity method (see Fig. 1), reducing the mass flow rate and increasing the transportation time of LNG [14]. In horizontal and slightly inclined pipelines at low flow rates, LNG is transferred in a stratified mode (Fig. 3): the liquid phase of LNG is entirely concentrated in the lower part of the pipeline, and the vapor phase is in its upper part, therefore, the disturbance of circulation and the appearance of steam locks on these areas does not occur [14].

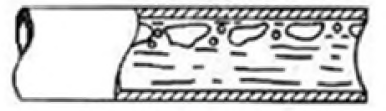

a

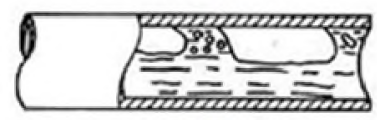

b

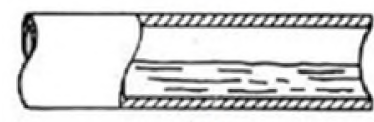

c

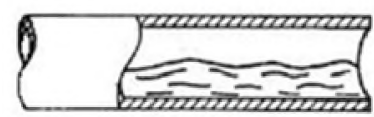

d

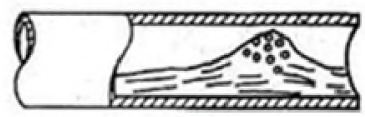

e
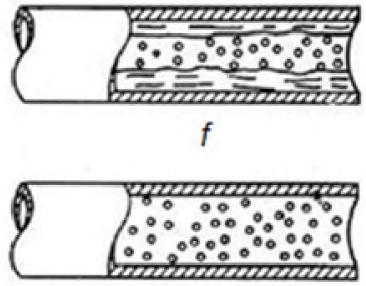

g

Direction of flow
Figure 3: Flow modes in horizontal pipelines:

a - bubble; b - cork; c - stratified; $d$ - wave; e - slug;

$f$ - circular; $g$ - emulsion.

\section{MATERIALS AND METHODS}

The efficiency of LNG transmission through a pipeline largely depends on the specific design of cryogenic pipelines and their thermal insulation. Basically, for cryogenic pipelines vacuum types of thermal insulation are used: vacuum-powder, layered-vacuum or pure vacuum (Fig. 4), which makes it possible to reduce heat fluxes to minimum values [9] to [10]. At the same time, pipelines with volumetric thermal insulation are used: bulk, porous and fibrous thermal insulation. Domestic and foreign experts recommend foamed materials as thermal insulation: polyurethane foam, expanded polystyrene, cork, foamed epoxy resin, foam glass [9], [15]. Designs of a pipeline for transferring a cryogenic liquid from one reservoir to another are known from patent sources (Figure 5), which makes it possible to remove the formed vapor phase in the vertical section of the pipeline [16]. 

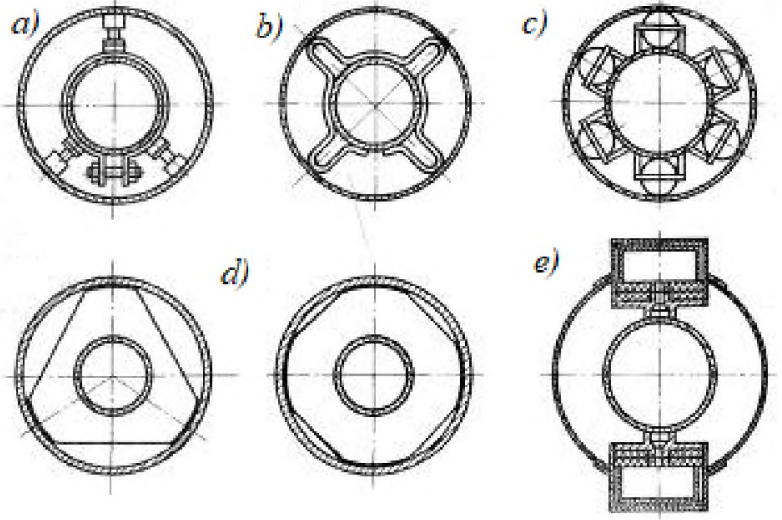

Figure 4: Structures of supports for the inner pipe in cryogenic pipelines:

a) - finger; b) - wire; c) - ballpoint; d) - disk; e) - trunnion

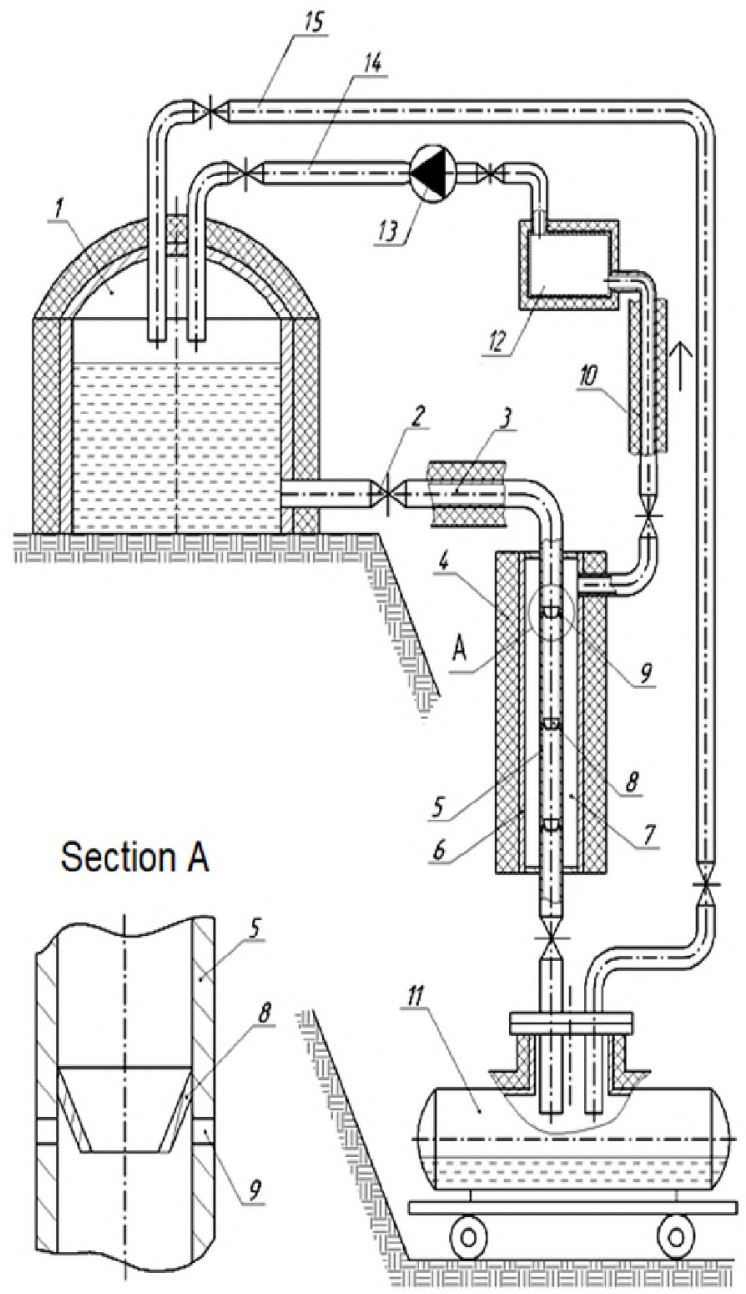

Figure 5: Structural diagram of LNG transmission through a pipeline by the gravity method:

1 - LNG storage; 2 - shut-off valves;

\section{3 - cryogenic pipeline;}

4 - thermal insulation of volumetric type; 5 - inner pipe;

6 - outer pipe; 7 - annular space; 8 - flow constriction element; 9 - holes; 10 - prefabricated gas outlet;

11 - transport tank; 12 - receiver; 13 - foreline pump;

14 - return gas pipeline; 15 - leveling gas pipeline.
Sources [16] to [17] propose a mathematical model of LNG transmission through a pipeline by the gravity method and a calculation method that allows determining the length of a single-phase LNG flow section and its transportation parameters: pressure $p$, temperature $T$, mass flow rate $G$ (Fig. 6).

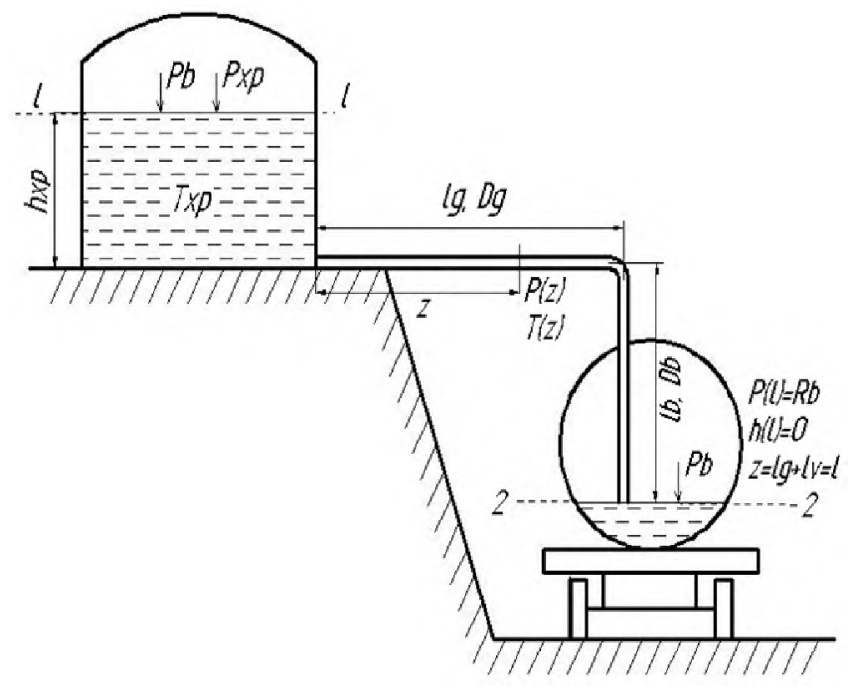

Figure 6: Design scheme for the transfer of LNG through the pipeline from the tank to the tank by the gravity method

LNG is transported through the pipeline under the influence of the available pressure drop in the storage and in the receiving tank and is characterized by the following parameters: pressure $P_{v x}$, temperature $T_{x}$, mass flow rate $G_{v x}=G_{1}$. The pipeline consists of horizontal and vertical sections and has thermal insulation with a thickness of $\delta$ with a thermal conductivity coefficient $\lambda$. The ambient temperature is assumed to be a constant $T_{n}=$ const.

\section{RESULTS}

Calculation of heat gains to LNG is carried out according to the well-known laws of the theory of heat conduction and convective heat transfer: the Fourier law and the Newton's law of cooling. As a result of heat inflows $q$ from the environment and a pressure drop in the pipeline $\Delta p$ because of the hydraulic resistance of the LNG pipeline at a certain distance from the inlet $z=l /$ reaches the saturation state with the parameters $T(I)=T^{\prime}, p$ $\left(I^{\prime}\right)=p^{\prime}, G_{1}[11]$ to [12], [17]. Transportation parameters of the LNG through a free-flow pipeline are close to the saturation line, therefore, even insignificant changes in pressure and temperature can lead to the evaporation of a part of the LNG and the appearance of a two-phase vapor-liquid flow, which significantly reduces the efficiency of LNG transfer by a free-flow method. Therefore, when calculating the parameters of LNG transportation through a pipeline, one should take into account changes in the thermophysical properties of LNG [18] to [19].

Based on the above, the length of the section of the sin- 
gle-phase flow of LNG through the pipeline is determined by the expression:

$$
l^{\prime}=\frac{103+0,000083 \cdot \mathrm{p}_{v h}-\mathrm{T}_{v h}}{0,000083 \cdot \mathrm{K}_{g}+\mathrm{a}_{1}-\mathrm{a}_{2} \mathrm{~T}_{v h}}
$$

where $a_{1}, a_{2}$ are complex quantities that take into account the effect of heat inflows from the environment and the parameters of LNG transportation on its temperature:

$a_{1}=\frac{\pi D \lambda T_{n}}{G_{1} c_{P} \delta}+\frac{\lambda_{m p} G_{1}^{2}}{2 D A^{2} \rho^{2} c_{P}}-\frac{g \cos \alpha}{c_{P}}$

$k_{\mathrm{f}}$-specific pressure losses in the horizontal section of the pipeline, $\mathrm{Pa} / \mathrm{m}$;

$\kappa_{g}=\frac{\lambda_{m p} \rho W_{g}^{2}}{2 D_{g}}$

Below this cut, there is a two-phase flow of LNG with the parameters $T_{\mathrm{g}}, p_{\mathrm{cm}}, G_{\mathrm{cm}}, x$. Calculation of pressure losses in the section of a two-phase LNG flow using the formulas for a single-phase flow leads to significantly underestimated results [12], [17]. In engineering practice, to calculate two-phase flows, simplified methods are usually used that are not related to the consideration of specific flow regimes: a model with phase slip (Lockhart-Martinelli correlation) and a homogeneous model [14], [20] to [21]. When calculating a two-phase flow according to the model with phase slip, pressure losses in a turbulent flow regime are determined by the equation [14]:

$\left(\frac{\Delta p}{\Delta l}\right)_{c m}=\left(\frac{\Delta p}{\Delta l}\right)_{j 0} \cdot(1-x)^{1,75} \cdot \Phi_{j}^{2}$,

where $(p / l) j$ is a pressure drop per unit length of the pipeline during the movement of the liquid phase at full flow rate $G=G_{g}+G_{i j}$, is determined by the well-known Darcy-Weisbach equation, $\mathrm{Pa} / \mathrm{m} ; \mathrm{x}$ is the mass steam content of the flow; $\Phi \mathrm{j}$ is a function expressing the ratio of the pressure loss of a two-phase mixture to the pressure loss of a single-phase liquid. The influence of heat inflows on the hydrodynamics of the flow is taken into account by changing the mass steam content $x$ along the length of the pipeline. The function $\Phi_{j}$ in expression (5) is determined graphically (Fig. 7) depending on the parameter [14]:

$\chi=\left(\frac{\rho_{g}}{\rho_{j}}\right)^{0,5} \cdot\left(\frac{\mu_{j}}{\mu_{g}}\right)^{0,125} \cdot\left(\frac{1}{x}-1\right)^{0,875}$

where $p_{g}, \rho_{s}$ are density of vapor and liquid phases, respectively, $\mathrm{kg} / \mathrm{m}^{3} ; \mu_{\mathrm{g}}, \mu_{\mathrm{j}}$ - dynamic viscosity of the vapor and liquid phases, respectively, Pa.s.

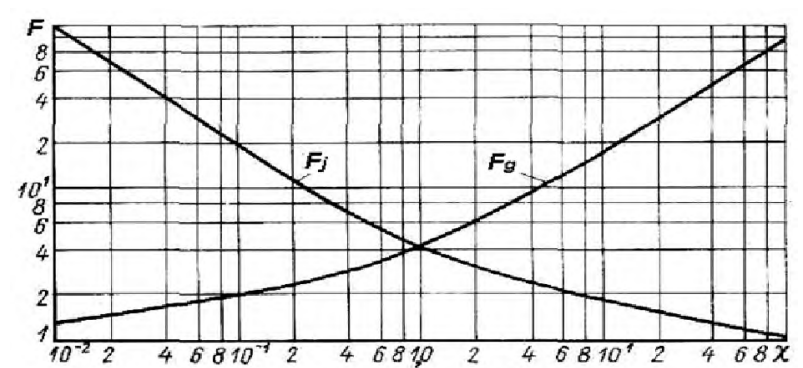

Figure 7: The ratio between $\Phi g(x) \cup \Phi_{j}(x)$ at turbulent flow of phases
At low steam contents of the flow and high mass velocities, the homogeneous model has the greatest agreement with the experimental data. The essence of the model is that a two-phase flow is considered as a single-phase flow, in which the specific volume in each section of such a flow is related to the mass vapor content and the specific volume of each of the phases [20] to [21]:

$$
v_{c m}=v_{j}(1-x)+v_{g} \cdot x
$$

The equation for calculating friction losses is written in a form similar to the Darcy-Weisbach equation [20] to [21]:

$$
\left(\frac{\Delta p}{\Delta l}\right)_{c m}=\frac{\lambda_{c m}(\rho W)^{2} v_{c m}}{2 D}
$$

where $\lambda_{\mathrm{cm}}$ is the coefficient of resistance of a two-phase flow, which can be represented by the coefficient of resistance of a single-phase flow $\lambda$ tr and some empirical function $\psi$ of the parameters of a two-phase flow, i.e.

$$
\lambda_{\mathrm{cm}}=\psi \cdot \lambda_{\mathrm{tr}}
$$

In view of the complex nature of the dependence of $\psi$ on the operating parameters of the two-phase flow, in engineering calculations, $\psi=1$ is taken. The main assumptions of the homogeneous model consist in the assumption of the equality of the linear velocities of vapor and liquid, the thermodynamic equilibrium of phases, and the applicability of the dependences to the two-phase flow for calculating the friction coefficient of a single-phase flow [20] to [21]. Having analyzed the known mathematical models of two-phase liquid flows, the authors proposed the following method for calculating a two-phase LNG flow. The initial data for calculating the parameters of the two-phase LNG flow are the values of the parameters $T^{\prime}, p^{\prime}, I^{\prime}$, obtained as a result of calculating the single-phase flow [11] to [12], [17]. The section of the pipeline $I_{c m}=I-I^{\prime}$, where liquid evaporation takes place, is divided into equal segments Delta I. Within each segment, the mass vapor content $x$ and the parameters of each of the phases are taken to be constant. At the end of each section, the steam content and pressure loss are determined. The mass vapor content in the section $\mathrm{li}+\mathrm{l}$ is determined by the vapor content of the flow in the previous section li and the increase in the vapor content in the segment Delta I=|i+1-I due to the heat gain and pressure drop over the saturated liquid

$$
x_{i+1}=x_{i}+\frac{4 q \cdot \Delta l}{D \cdot \rho \cdot W \cdot r}+\frac{i_{S}\left(p_{i}\right)-i_{S}\left(p_{l-1}\right)}{r}
$$

where $i_{s}(p i)$ is the enthalpy on the LNG saturation line at a pressure $p_{i}, \mathrm{~J} / \mathrm{kg} ; \mathrm{r}-$ specific heat of vaporization, $\mathrm{J} /$ $\mathrm{kg}$; $\mathrm{q}$ is the amount of heat input to LNG, which can be determined by the formula:

$$
q_{l}=\frac{2 \pi \lambda_{\text {ins }}\left(T_{H}-T_{L N G}\right)}{\ln \left(D_{\text {ins }} / D\right)}
$$

The pressure at the end of each segment in the section $\mathrm{I}_{\mathrm{i}+1}$ is related to the pressure in the section $\mathrm{I}_{\mathrm{i}}$ as follows: 


$$
p_{i+1}=p_{i}-\Delta p_{c m \cdot t r}-\frac{\Delta l \cdot \cos \alpha}{v_{c M}}
$$

where $a$ is the angle of inclination of the segment DI to the vertical, $u_{c m}$ - is the specific volume of the vapor-liquid mixture, $\mathrm{m}^{3} / \mathrm{kg}$. When moving to the next segment, the change in the vapor content and density of the vapor phase due to the heat gain and pressure drop in the previous segment is taken into account. To calculate the pressure loss by friction $\Delta \mathrm{p}_{\mathrm{cm} \text { tr }}$ in a two-phase flow on the segments delta I he relations of both the model with phase slip and the homogeneous model can be taken. The calculation is correct if the condition is met:

$$
\frac{p_{p . v v k h}-p_{v y k h}}{p_{v y k} h}<\varepsilon_{\text {, }}
$$

where $p_{p \text { vukh }}$ is the design pressure at the end of the pipeline, $\mathrm{Pa} ; \mathrm{p}_{\mathrm{vykh}}$ is a predetermined pressure value, $\mathrm{Pa} ; \mathrm{E}$ is specified relative calculation error. If the calculated pressure turns out to be higher than the specified value, then the flow rate should be increased and the calculation repeated; if the design pressure turns out to be lower, then the product flow rate should be reduced and the calculation repeated. The values $W$ and $x_{\text {vukh }}$, corresponding to relation (13) will be the required ones [11] to [12], [17]

\section{CONCLUSION}

The main findings of this article are:

1. When LNG is dispensed from the storage facility by the gravity method, the subcooling of LNG at the inlet to the pipeline is provided by the hydrostatic head of the liquid column and the excess pressure of LNG vapor in the storage facility.

2. During transportation, the temperature of LNG along the length of the pipeline changes insignificantly due to heat inflows, taking into account the use of effective thermal insulation, and the state of LNG saturation is achieved mainly due to pressure losses to overcome the hydraulic resistance of the pipeline below the pressure of saturated LNG vapors.

3. With a long pipeline length, LNG boils in a certain section of the pipeline and is then transmitted in a two-phase flow, creating steam plugs in the vertical section of the pipeline with the possibility of overturning the circulation.

4. Methods for calculating pressure losses in sections of single-phase and two-phase LNG flow are proposed. The section of the two-phase LNG flow is divided into segments, within which the steam content $x$ and the parameters of each of the phases are taken constant. To calculate the pressure loss by friction $\Delta$ pcm.tr on the segments delta I the ratios of both the model with phase slip (5-6) and the homogeneous model (7-12) can be adopted.

\section{REFERENCES}

1. Barmin I.V., Kunis I.D. (2009). Liquefied natural gas yesterday, today, tomorrow: monograph. Publishing House of Bauman Moscow State Technical University.

2. Al-Breiki, M., Bicer, Y. (2021). Comparative life cycle assessment of sustainable energy carriers including production, storage, overseas transport and utilization. Journal of Cleaner Production, vol. 279, DOI:10.1016/j.jclepro.2020.123481.

3. Jiajia Liu. On the issue of supply chain management of liquefied natural and hydrocarbon gas (2021). Modern aspects of the economy, № 1 (281), 30-42.

4. Inkov, A.P., Skorodumov, B.A., Darbinyan, R.V. (2003). Decentralized energy supply using liquefied natural gas. Ventilation, heating, air conditioning, heat supply and building thermal physics (AVOK), № 2 .

5. Babich S.V., Bulaeva M.M. (2019). Russian liquefied natural gas and Russian pipeline gas in the European market: competition or synergy. Bulletin of Eurasian Science, vol. 11, №. 6, p. 9.

6. Ezhov, V.S., Semicheva, N.E., Shchedrina, G.G. (2021). Technology of Complex Treatment of Natural Gas before its Delivery to the Consumer. Chemical and Petroleum Engineering, vol. 56, no. 9-10, 721725, DOI:10.1007/s10556-021-00834-y.

7. Mazura, I.I., Shapira, V.D. (2005). Oil and gas construction: Textbook for students specializing in "Management in the oil and gas complex". Moscow, Omega.

8. Sazonov, A. Y., Mokhov, A. M., Mulenko, V. V., Tumanyan, A. K., Frankov, A. M., \& Voronova, V. V. (2020). Exploratory research for developing advanced pumping and compressor equipment adapted to abnormal operating conditions of oil and gas production. Journal of Applied Engineering Science, vol. 18(4), $467-474$, DOl:10.5937/jaes0-26356.

9. Fastovsky V.G., Petrovsky Yu.O. Rovensky A.E. (1967). Cryogenic technology. Moscow, Energiya.

10. 10. llyinsky A.A. (1976). Transport and storage of industrial liquefied gases. Moscow, Chemistry.

11. Polozov, A.E., Zhmakin, V.A. (2007). Effective scheme of low-pressure LNG transmission through technological pipelines. Gas industry, Moscow, Gazoil press, 68-70.

12. Zhmakin, V.A. (2007). Development of methods and technical solutions for the transportation of liquefied natural gas through low-pressure pipelines. Dissertation for the degree of candidate of technical sciences. Moscow. 
13. Preobrazhensky, N.I. (1975). Liquefied petroleum gases. Leningrad, Nedra.

14. Kutepov, A.M., Sterman, L.S., Styushin, N.G. (1986). Hydrodynamics and heat transfer during vaporization: Textbook for universities. - 3rd ed. Moscow, Higher. shk.

15. Polozov, A.E. (1988). Trunk pipelines of cooled and liquefied natural gas. Syktyvkar.

16. Polozov, A.E., Zhmakin, V.A. (2006). Patent 58658 RF, F17D 1/13, F16L 9/18. Pipeline for the transfer of cryogenic liquid (Russia), № 2006116911/22; Stated May 16, 2006; Publ. November 27, 2006, bul. № 33.

17. Zhmakin, V.A. (2019). Development of energy-saving and environmentally safe technology for the transportation of liquefied natural gas through technological pipelines of the station for receiving, storing and delivering liquefied natural gas to consumers. Kursk, University Book.

18. Zagoruchenko, V.A., Zhuravlev, A.M. (1969), Thermophysical properties of gaseous and liquid methane. Moscow.
19. Shalovnikov E.A., Prakhova M.Y.1, Khoroshavina YE.A. (2020). Mathematical model for determination of liquefied natural gas density by its parameters and composition. IOP Conference Series: Earth and Environmental Science. International Science and Technology Conference "EarthScience". Russky Island, December 10-12, 2019. DOI: 10.1088/17551315/459/6/062007.

20. Lervåg, K.Y. Skarsvåg, H.L., Aursand, E., Ouassou, J.A., Hammer, M.a,Reigstad, G., Ervik, Å., Fyhn, E.H., Gjennestad, M.A., Aursand, P., Wilhelmsen, O. (2021). A combined fluid-dynamic and thermodynamic model to predict the onset of rapid phase transitions in LNG spills. Journal of Loss Prevention in the Process Industries, vol. 69, DOl:10.1016/j. jlp.2020.104354.

21. Karyakina E.D., Shammazov I.A., Shalygin A.V. (2021) Main aspects of liquefied natural gas process line thermal and hydraulic calculations. IOP Conference Series: Earth and Environmental Science. Krasnoyarsk Science and Technology City Hall. Krasnoyarsk, Russian Federation, DOI: 10.1088/17551315--/677/5/052056. 